\title{
Causes Of Low Efficiency Of Combined Ventilation System In Coal Mines In Resolving The Problem Of Air Leaks (Inflows) Between Levels And Surface
}

\author{
Valeriy Popov ${ }^{1 *}$, Yuriy Filatov ${ }^{1}$, Hee Lee $^{2}$, and Anatoliy Golik ${ }^{2}$ \\ ${ }^{1} \mathrm{JSC}$ «NC VostNII», 650002, 3 Institutskaya Str., Kemerovo, Russia
}

\begin{abstract}
The paper discusses the problem of the underground mining safety control. The long-term air intake to coal accumulations is reviewed as one of the reasons of endogenous fires during mining. The methods of combating air leaks (inflows) in order to prevent endogenous fires are analyzed. The calculations showing the discrepancy between the design calculations for the mine ventilation, disregarding a number of mining-andgeological and mining-engineering factors, and the actual conditions of mining are given. It is proved that the conversion of operating mines to combined (pressure and exhaust) ventilation system in order to reduce the endogenous fire hazard of underground mining is unreasonable due to impossibility of providing an optimal distribution of aerodynamic pressure in mines. The conversion does not exclude the entry of air into potentially hazardous zones of endogenous fires. The essence of the combined application of positive and negative control methods for the distribution of air pressure is revealed. It consists of air doors installation in easily ventilated airways and installation of pressure equalization chambers equipped with auxiliary fans near the stoppings, working sections and in parallel airways. The effectiveness of the combined application of negative and positive control methods for the air pressure distribution in order to reduce endogenous fire hazard of mining operations is proved.
\end{abstract}

\section{Introduction}

Currently, the principal direction of the technical policy in the coal industry is the abandonment of the extensive development path. In future, the coal production should be increased mainly through the reconstruction of existing enterprises and their technical reequipment, concentration and intensification of the mining operations, which will lead to an accelerated dynamics of deep mining and, consequently, deterioration of the geological and mine-engineering factors. These circumstances contribute to the frequency and severity of accidents, and therefore, the problem of ensuring the proper safety of underground mining is of significant importance.

The analysis of accidents in the Kuzbass mines showed that over the last decade more

* Corresponding author: a.zakirova@nc-vostnii.ru 
than $30 \%$ of such accidents were endogenous fires. In this regard, prevention and control of dustiness and endogenous fire are among the most important issues associated with the overall problem of lowering the accident rate in the coal industry. Thus, many Russian and foreign researchers addressed the issue of dust control in coal mines [1-9], highlighting it as one of the factors affecting industrial safety. Some researchers offered various methods of dust control and dust removal [10-15].

\section{Materials and methods}

A necessary and virtually sufficient condition for the formation of a spontaneous ignition source in a fire-hazardous seam is long-term (exceeding the incubation period) airflow to accumulations of broken-down, collapsed or loose coal; such air flow contributes to the oxidation processes and leads to the breaking-out and development of endogenous fires.

To exclude such negative consequences, it is necessary either to avoid loss of coal, or to prevent the flow of oxygen to the coal accumulations. Considering that the first condition is nearly impracticable at the modern technical level of underground coal mining development, the main attention should be given to the second solution.

Based on the extensive scientific research and experiments, the following methods for combating air leaks (inflows) have been developed:

- isolation of mined-out working fields, blocks, extraction columns, sections of certain inactive workings,

- ensuring the optimal distribution of aerodynamic pressure along the network of mine workings, which excludes the entry of air into potentially hazardous, fire-prone areas with the use of negative and positive control methods;

- use of the combined ventilation system to maintain the required aerodynamic head pressure in the extraction areas.

The existing means and methods of isolation include the use of rather expensive airtight materials, structures and fixtures. However, in spite of the significant material and labor costs of isolation works, the commonly required conditions of preventing oxidation in isolated workings are not ensured.

Better effect can be achieved by application of aerodynamic means to combat air leaks (inflows). Such means are based on the regulation of the distribution of ventilation pressure and air flows in the network of mine workings, using negative and positive control methods.

The negative control method of regulation consists in the installation of ventilating windows in easily ventilated branches. At that, the resistance of the window determines the amount of flowing air, and the place of installation, the distribution of ventilation pressure in the branch. This makes it possible to control the ventilation pressure by installing ventilation windows simultaneously at both ends of the ventilated branch. The total aerodynamic resistance of these windows provides flow of the required amount of air, and the ratio of their resistances creates the necessary ventilation pressure inside the branch.

The required values of the ventilation pressure at a given air volume distribution can be ensured simultaneously in several different branches with the help of ventilation windows if each branch has only one point in which the required ventilating pressure should be provided, and if no branch with a given pressure is ventilated in sequence with another branch. Such conditions limit the applicability of this method.

The positive control method has a wider use. Here, the air terminal boxes equipped with auxiliary fans are installed at separate stoppings, in active working faces and in parallel branches.

A special place among the aerodynamic methods of combating air leaks (inflows) belongs to the combined method of ventilating the mines. It is typically used to create a 
zero-pressure zone in the extraction areas and, thus, reduce the amount of air flowing through the mined-out sections to minimum values. Theoretically, this method of ventilation should give the same effect as the use of air terminal boxes. However, in practice, after conversion of the operating mines to combined ventilation, increase in the level of endogenous fire safety of mining operations is, as a rule, not observed. This can be explained by the fact that, due to low compressions of the forced-draught fans, the zeropressure zone is mainly located near the downcast shafts, while in the extraction areas negative pressure occurs. In such cases, the combined ventilation is equivalent to the exhaust ventilation in terms of fire safety.

Insufficient compression of the forced-draught fans in the combined ventilation system is primarily determined by the fact that a number of factors are not taken into account in the ventilation system design. Thus, the designed rate of surface leakage, equal to $10 \%$ (recently, 20\%), can be achieved only in special airshafts that are not used for lifting operations. As targeted aerodynamic surveys showed, in the cage shafts leakage is $30-40 \%$ in average and in some cases reaches $50 \%$. There are still no reliable methods of sealing the shafts equipped with a lift, so that the actual surface leaks would be equal to the designed ones. With poor sealing of the overhead buildings, the aerodynamic resistance, that the ventilator works for, reduces significantly and, as a result, the compression on the pressure side falls lower than designed.

Low compressions of the forced-draught fans is also pre-determined by the fact that the amount of air supplied to the mine is often greater than the designed due to the intensified production, as compared to the designed scope, and inaccurate gas content forecast. The amount of flowing air can be augmented by improving the capacity of the forced-draught fans or increasing their number. In such cases, the actual individual aerodynamic characteristics of the fans are aligned, which leads to a drop in their compressions.

When choosing forced-draught fans, as a rule, the loss of negative pressure in the air heater and air supply duct is not taken into account; it is assumed that the differential pressure created by the forced-draught fan is used only to overcome the resistance of underground workings, starting from the evasee. In fact, as the negative pressure surveys showed, up to $50 \%$ of the differential pressure is consumed by the forced-draught fans on the suction side, which leads to a nearly twofold drop in compression.

It should also be noted that such factor as the change in aerodynamic parameters of the mine ventilation networks in the course of operations is underestimated. In connection with the extraction of the upper horizons and application of the pillarless technology, the worked-out space acquired a special role in setting of ventilation modes. Large areas and volumes of excavations, numerous aerodynamic connections with the operated workings and the soil surface significantly affect the ventilation characteristics of the mines and the distribution of air between the objects of ventilation. The presence of numerous yet neglected parallel air paths in the aerodynamic systems pre-determines the displacement of the fan operation points towards the axis of abscissas, and, as a consequence, the decrease in the aerodynamic pressure heads developed by them.

Eventually, neglect of the above factors leads to the fact that with the combined ventilation, the zero-compression point often appears to be directly under the downcast shaft, instead of the extraction area, and the operation of the forced-draught fan has no effect on the endogenous fire safety of mining operations.

Consider a specific example. Figure 1 shows a design model of the mine ventilation system. 


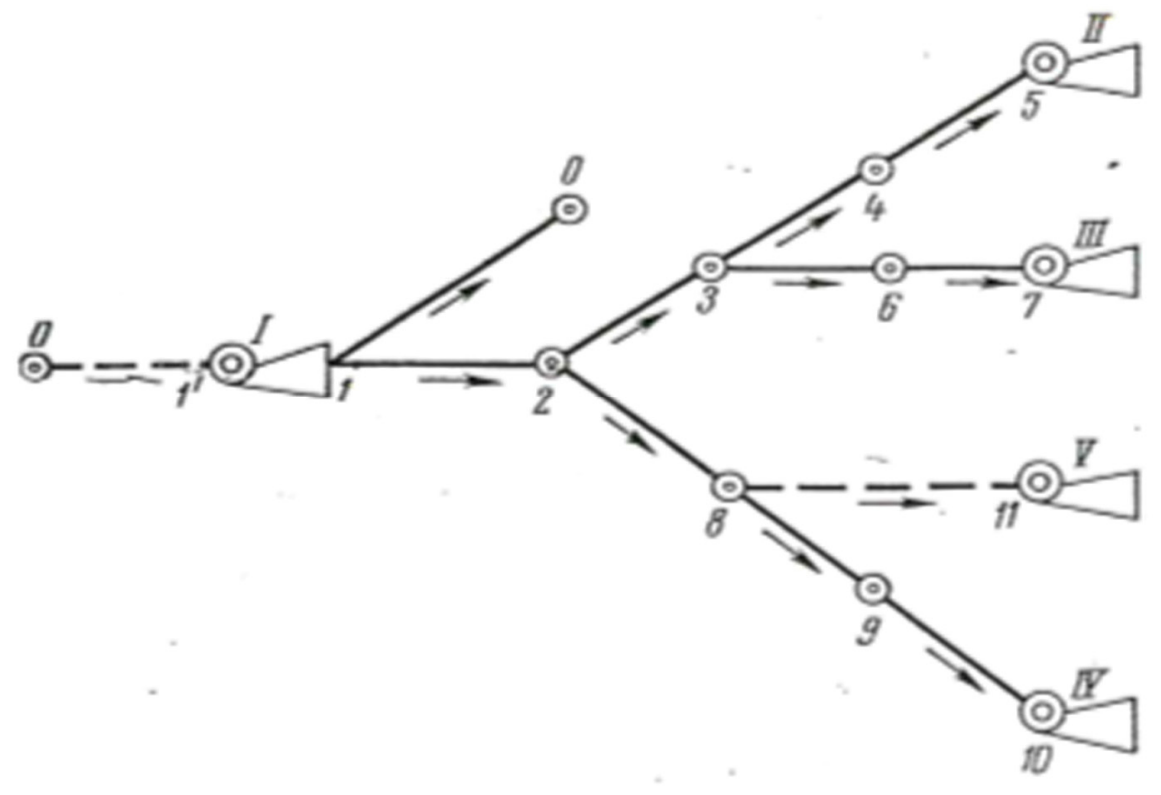

Fig. 1. Design model of the mine ventilation system.

At leakage resistance of $8.4 \mathrm{k \mu}$ (branch 1-0) and the operating modes of the forceddraught fans specified in Table 2 (Variant I), the BOD-21 fan $\left(\mathrm{n}=750 \mathrm{rpm}, \Theta=30^{\circ}\right)$ will operate in the mode denoted by point $a$ in Figure 2 (point $a^{\prime}$ denotes the operating mode of the fan in the mine). Air leakage (10\%) corresponds to the designed value. The zeropressure zone is located in points 4, 6, 9 (Figure 1), which corresponds to the extraction areas.

If now the resistance of leakage paths is reduced from $8.4 \mathrm{k \mu}$ to $0.39 \mathrm{k} \mu$, then in order to maintain the amount of air entering the mine at the same level, it is necessary that the suction fans worked in the modes given in Table 1 (Option II).

Table 1. Operating modes of the forced-draught fans

\begin{tabular}{|l|l|l|l|l|l|l|l|l|}
\hline \multirow{2}{*}{$\begin{array}{l}\text { No. of the fan } \\
\text { in Figure1 }\end{array}$} & \multicolumn{9}{|l|}{ Operating modes of the forced-draught fans } \\
\cline { 2 - 9 } & \begin{tabular}{l} 
Option I \\
\cline { 2 - 9 } \\
\cline { 2 - 9 } \\
daPa
\end{tabular} & $\begin{array}{l}\text { Q, } \\
\mathrm{m}^{3} / \mathrm{s}\end{array}$ & $\begin{array}{l}\text { Option II } \\
\text { daPa }\end{array}$ & $\begin{array}{l}\text { Q, } \\
\mathrm{m}^{3} / \mathrm{s}\end{array}$ & $\begin{array}{l}\text { Option III } \\
\text { daPa }\end{array}$ & $\begin{array}{l}\text { Q, } \\
\mathrm{m}^{3} / \mathrm{s}\end{array}$ & $\begin{array}{l}\text { Option IV } \\
\text { daPa }\end{array}$ & $\begin{array}{l}\text { Q, } \\
\mathrm{m}^{3 /} \\
\mathrm{s}\end{array}$ \\
\hline I & 210 & 50 & 100 & 61 & 131 & 57.5 & 91.0 & 62 \\
\hline II & 20 & 15 & 130 & 15 & 169 & 15.0 & 274.2 & 15 \\
\hline III & 16 & 15 & 126 & 15 & 165 & 15.0 & 270.2 & 15 \\
\hline IV & 15 & 15 & 125 & 15 & 164 & 15.0 & 358.7 & 15 \\
\hline V & - & - & - & - & - & - & 290.0 & 12 \\
\hline
\end{tabular}

Then the forced-draught fan will operate in the new mode denoted by the point $b$ in Figure 2, and the leakage will be $26 \%$ (point $b^{\prime}$ indicates the operating mode of the fan, modified to the mine conditions). Comparison of the two operating modes of the forceddraught fan (points $a$ and $b$ ) shows that the increase in the leakage rate sharply reduces the compression of the VOD-21 fan.

Introduction of an air heater and its duct into the resistance scheme will require the suction fans to be transferred to the operating modes given in Table 2 (Option III) in order to maintain the calculated amount of air. At that, the total differential pressure of the 
forced-draught fans will increase (refer to point $c$ in Figure 2), but the compression on the pressure side will be less than it would be without an air heater (point $c^{\prime}$ ).

Thus, the discrepancy between the actual leaks and the designed ones and the neglect of the depression losses on the suction side lead to the fact that the forced-draught fan develops the compression of $61 \mathrm{daPa}$, instead of the initially adopted compression of 210 $\mathrm{daPa}$. As a result, the negative pressure of $149 \mathrm{daPa}$ occurs in points 4, 6, 9 (Figure 1), instead of the zero pressure.

If now the air intake to the mine is increased from $45 \mathrm{~m}^{3} / \mathrm{s}$ to $57 \mathrm{~m}^{3} / \mathrm{s}$ by changing the operating mode of the suction fans and connecting an additional suction fan, the operating mode point of the forced-draught fan will move downward along the descending line of pressure characteristics and take the position indicated by the letter $d$ in Figure 2, while the compression will be only $10 \mathrm{daPa}$ (point $d^{\prime}$ ). At such compression value, the zero pressure zone does not reach beyond the shaft bottom and the application of the combined ventilation method, according to the pressure distribution conditions, substantially loses its meaning.

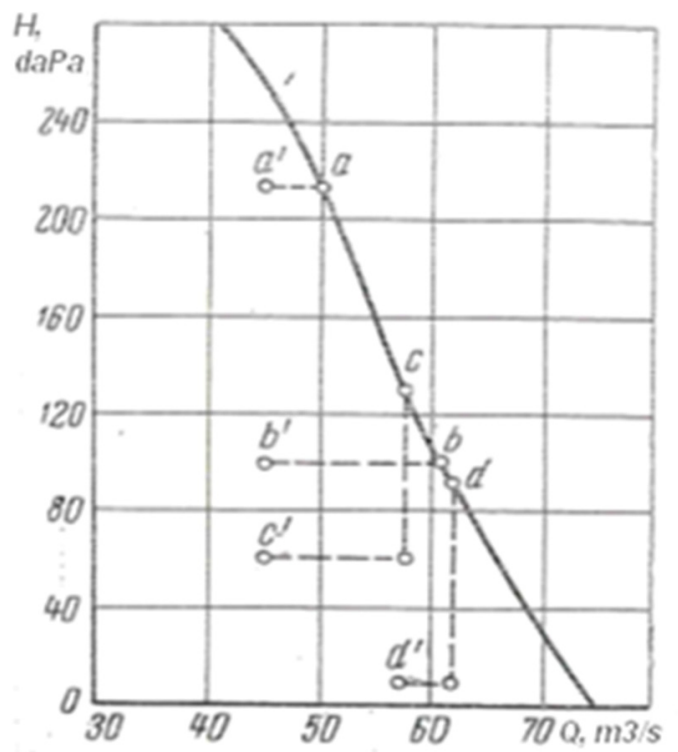

Fig. 2. Changes in operating modes of the forced-draught fan at various leakage values and upon introduction of the air heating duct and the additional suction fan.

\section{Conclusions}

Thus, it can be concluded:

Firstly, conversion of the operating mines to combined ventilation in order to reduce the endogenous fire hazard of mining operations is impractical, for it is virtually impossible to ensure the optimal distribution of aerodynamic pressure in the existing ventilation networks and exclude the possibility of air cross-flows over the mined-out areas and between the working horizons and the soil surface.

Secondly, on the basis of the aerodynamic principle, the proper prevention of air leaks (inflows) into the potentially hazardous, fire-prone areas can only be achieved by the complex application of negative and positive methods of the ventilation pressure distribution. 


\section{References}

1. H. Breuer, Glückauf, 108:18, 806 (1972)

2. A.G. French, Proceedings of the European Economic Communities Conference on Dust Control, 57 (1983)

3. G.V.R. Goodman, T.W. Beck, D.E. Pollock, J.F. Colinet, J.A. Organiscak, Proceedings of the 11th U.S., North American Mine Ventilation Symposium London, 211 (2006)

4. A.B. Cecala, J.A. Organiscak, W.A. Heitbrink, J.A. Zimmer, T. Fisher, R.E. Gresh, J.D. Ashley Transactions of Society for Mining, Metallurgy, and Exploration, 314, 31 (2003)

5. F.N. Kissell, G.V.R. Goodman, Continuous miner and roof bolter dust control. In: Handbook for dust control in mining Pittsburgh, 23 (DHHS, NIOSH Pub., 2003)

6. G.J. Chekan, J.M. Listak, J.F. Colinet Proceedings of the Seventh International Mine Ventilation Congress, 291 (2001)

7. J.M. Listak, G.J. Chekan, J.F. Colinet, Transactions of Society for Mining, Metallurgy, and Exploration, 310, 155 (2001)

8. T.F. Tomb, Transactions of Society for Mining, Metallurgy, and Exploration, 288, 1874 (1992)

9. J.A. Organiscak, A.B. Cecala, E.D. Thimons, W.A. Heitbrink, M. Schmitz, E. Ahrenholtz, Yernberg WR, ed. Transactions of Society for Mining, Metallurgy, and Exploration, 314, 145 (2003)

10. J.F. Colinet, R.A. Jankowski, Transactions of Society for Mining, Metallurgy, and Exploration. 302, 104 (1996)

11. K.G. Fields, D.J. Atchison, R.A. Haney, Proceedings of the Third Symposium on Respirable Dust in the Mineral Industries, 349 (1991)

12. F.N. Kissell, Dust control methods in tunnels and underground mines. In: Handbook for dust control in mining, 3 (DHHS, NIOSH, 2003)

13. G.J. Chekan, J.M. Listak, J.F. Colinet, Yernberg WR, ed. Transactions of Society for Mining, Metallurgy, and Exploration. Littleton, 316, 186 (2004)

14. J.F. Colinet, E.R. Spencer, R.A. Jankowski, Proceedings of the Sixth International Mine Ventilation Congress, 55, 345 (1997)

15. E.F. Divers, R.A. Jankowski, J. Kelly, Proceedings of the Third U.S. Mine Ventilation Symposium, 85 (1987) 